\title{
First-ever ischemic stroke in elderly patients: predictors of functional outcome following carotid artery stenting
}

This article was published in the following Dove Press journal:

Clinical Interventions in Aging

26 July 2016

Number of times this article has been viewed

\author{
Chih-Ming $\operatorname{Lin}^{1,2}$ \\ Yu-Jun Chang ${ }^{3}$ \\ Chi-Kuang $\mathrm{Liu}^{4}$ \\ Cheng-Sheng $\mathrm{Yu}^{5}$ \\ Henry Horng-Shing $\mathrm{Lu}^{5}$ \\ 'Department of Neurology, Stroke \\ Center, Changhua Christian Hospital, \\ Changhua, ${ }^{2}$ Department of Biological \\ Science and Technology, National \\ Chiao Tung University, Hsinchu, \\ ${ }^{3}$ Epidemiology and Biostatistics \\ Center, Changhua Christian Hospital, \\ Changhua, ${ }^{4}$ Department of Medical \\ Imaging, Changhua Christian Hospital, \\ Changhua, ${ }^{5}$ Institute of Statistics and \\ Big Data Research Center, National \\ Chiao Tung University, Hsinchu, Taiwan
}

Correspondence: Henry Horng-Shing Lu Institute of Statistics and Big Data

Research Center, National Chiao

Tung University, I00I Ta Hsueh Road,

Hsinchu 300 I0, Taiwan

$\mathrm{Tel}+8863573$ I 870

Fax +886 35728745

Email hslu@stat.nctu.edu.tw

\begin{abstract}
Age is an important risk factor for stroke, and carotid artery stenosis is the primary cause of first-ever ischemic stroke. Timely intervention with stenting procedures can effectively prevent secondary stroke; however, the impact of stenting on various periprocedural physical functionalities has never been thoroughly investigated. The primary aim of this study was to investigate whether prestenting characteristics were associated with long-term functional outcomes in patients presenting with first-ever ischemic stroke. The secondary aim was to investigate whether patient age was an important factor in outcomes following stenting, measured by the modified Rankin scale (mRS). In total, 144 consecutive patients with first-ever ischemic stroke who underwent carotid artery stenting from January 2010 to November 2014 were included. Clinical data were obtained by review of medical records. The Barthel index (BI) and mRS were used to assess disability before stenting and at 12-month follow-up. In total, 72/144 patients showed improvement $(\mathrm{mRS}[+]), 71$ showed stationary and one showed deterioration in condition (mRS[-]). The prestenting parameters, ratio of cerebral blood volume (1.41 vs 1.2 for mRS[-] vs mRS[+]), BI (75 vs 85), and high-sensitivity C-reactive protein (hsCRP 5.0 vs 3.99), differed significantly between the two outcome groups $(P<0.05)$. The internal carotid artery/common carotid artery ratio $(P=0.011), \mathrm{BI}(P=0.019)$, ipsilateral internal carotid artery resistance index $(P=0.003)$, and $\mathrm{HbA1c}(P=0.039)$ were all factors significantly associated with patient age group. There was no significant association between age and poststenting outcome measured by $\mathrm{mRS}$ with $57 \%$ of patients in the $\geq 75$ years age group showing $\mathrm{mRS}(-)$ and $43 \%$ showing $\mathrm{mRS}(+)(P=0.371)$. Our findings indicate that in our elderly patient series, carotid artery stenting may benefit a significant proportion of carotid stenotic patients regardless of age. Ratio of cerebral blood volume, BI, and admission hsCRP could serve as important predictors of mRS improvement and may facilitate differentiation of patients at baseline.
\end{abstract}

Keywords: modified Rankin scale, resistance index, Barthel index, common carotid artery, cerebral blood volume ratio

\section{Introduction}

Ischemic stroke is a leading cause of death worldwide and although it may occur in people of all ages, risk increases significantly with age. ${ }^{1,2}$ People $>65$ years are around ten times more likely to suffer from a stroke than those in the 18- to 44-year age group. Risk of recurrence also increases with age. In Taiwan, the median age of stroke is around 70 years. Between 2000 and 2005, stroke mortality increased from 50 per 100,000 to 2,300 per 100,000 in the 50 - to 90 -year age group. ${ }^{3}$ For men, the highest prevalence of stroke mortality was in the 80- to 84-year age group, whereas for women, it was highest in those $>85$ years. $^{3}$ 
Approximately $25 \%-30 \%$ of all strokes result from large artery stenosis, in particular carotid artery stenosis. ${ }^{1,2,4}$ Studies have shown that patients with moderate to severe carotid artery stenosis involving lumen reduction of $>50 \%$ diameter are at heightened risk of developing new-onset ischemic stroke. ${ }^{5,6}$ Such patients should be offered carotid endarterectomy (CEA) or carotid artery stenting (CAS) at the earliest opportunity.

The current American Heart Association and the American Stroke Association Guideline ${ }^{7}$ recommends CEA for older patients, whose carotid system tends to be more tortuous. This procedure is advantageous as it enables the surgeon to visualize the stenosis although it requires longer healing time and may cause scarring. CAS still presents a viable alternative, particularly in younger patients and at hospitals that do not offer CEA. Furthermore, some patients and physicians prefer stenting because it is a less invasive procedure. In addition, a recent randomized controlled trial found that in patients with symptomatic carotid stenosis, the long-term functional outcomes were comparable for CAS and CEA with modified Rankin scores not differing significantly between treatment groups at follow-up. ${ }^{8}$

After stenting, long-term functional outcomes vary widely. In our experience, some patients, including those who fit the recommended criteria for stenting, become dependent on others for activities of daily living after the procedure. A large proportion of patients who have experienced their first ischemic stroke have underlying conditions or comorbidities that may adversely affect outcomes following stenting. The heterogeneity in outcomes following stenting and the propensity of underlying conditions suggest that it would be valuable to identify patient characteristics that predict outcomes following stenting and thus which patients are most likely to benefit from this procedure.

Little is known about functional outcomes after CAS in elderly patients who have had just one ischemic stroke. To address this gap in the evidence, long-term functional status was assessed 12 months after stenting in patients who had recently experienced their first ischemic stroke.

The primary aim of this study was to investigate whether prestenting characteristics were predictive of long-term functional outcome in patients with first-ever ischemic stroke. The secondary aim was to investigate whether patient age was an important factor in outcomes following stenting, measured by modified Rankin scale (mRS).

\section{Materials and methods}

In this retrospective study, we collected data from the medical records of consecutive patients who underwent CAS for first-ever ischemic stroke during the period January
2010 to November 2014 at the angiography laboratory of the Department of Medical Imaging, Changhua Christian Hospital. All patients had the procedure conducted by the same physician, as our institution has only one neurointerventionist (Dr Chi Kuang Liu).

Inclusion criteria included age $\geq 18$ years, no previous history of ischemic stroke, angiographic evidence of $>50 \%$ carotid stenosis, no other etiology of stroke that could explain the index event except for the critical carotid stenosis, no evidence of recurrent stroke during the study period, minimal or no rehabilitation treatment and no other alternative medicine treatment after the stenting procedure, and completion of at least 12 months of follow-up after stenting. We excluded patients with cerebral hemorrhage, those with cerebral arteriovenous malformations or aneurysms, patients lost to follow-up, and those who did not complete 12 months of follow-up after the stenting procedure.

A total of 144 patients fulfilled the inclusion criteria and were included in the study. All patients underwent a comprehensive history, physical examination, biochemistry, and carotid ultrasound investigations on admission and during the admission period. Cranial diffusion-weighted magnetic resonance imaging and angiography (MRI/A) and computed tomography angiography and perfusion $(\mathrm{CTA} / \mathrm{P})$ imaging were also conducted at these times. All patients underwent diagnostic digital subtraction angiography to confirm the lesion site and degree of the stenosis during the admission. Carotid stenting was subsequently implemented 1 month after the index stroke event. This study was approved by the Institutional Review Board of the Changhua Christian Hospital. The study was retrospective and the informed consent was not required by the Institutional Review Board of Changhua Christian Hospital.

\section{Baseline clinical characteristics}

Baseline demographic data and clinical characteristics were collected, including age, sex, and body mass index; baseline biochemistry data on admission, including low-density lipoprotein, high-sensitivity C-reactive protein (hsCRP), and glycated hemoglobin (HbAlc) levels; and evidence or history of chronic kidney disease, chronic heart failure, atrial fibrillation, gout, diabetes mellitus, hypertension, and dyslipidemia. Performance in activities of daily living was measured before stenting with the Barthel index (BI), and the degree of disability was measured with the modified mRS as previously described. ${ }^{9,10}$ The $\mathrm{mRS}$ score was assessed at least twice, before stenting and again at 12-month follow-up in an outpatient setting. Each assessment was conducted by two physicians, and any discrepancies were resolved by consultation with a third physician. Patients were stratified based on their net mRS score and age group. 


\section{Carotid ultrasound examination}

The cervical carotid artery was examined with a Philips iE33 7-Mhz linear transducer (San Jose, CA, USA). Patients were asked to tilt their head slightly to the contralateral side, and the transducer was placed on the neck. Initially, cross-sectional B mode scanning was performed to check for any intraluminal plaque, and the longitudinal screening method was adopted for confirmatory purposes. Plaque was classified into subtype 1, 2, 3, or 4 based on the International Classification System, as previously described. ${ }^{11}$ The classification of plaques was determined by two physicians, and any discrepancies were resolved by consultation with a third physician (kappa value: 0.91 ). Intima-media thickness (IMT) of the mid-portion of the common carotid artery (CCA) was measured on the ipsilateral side (symptomatic side of index stroke event). We also measured peak systolic velocity (PSV), end diastolic velocity (EDV), and resistance index (RI) (PSV-EDV/PSV) of the bilateral CCA, internal carotid artery (ICA), external carotid artery (ECA), and ophthalmic artery (OA) as well as reversal of blood flow in the OA. Forward flow was defined as blood flow directed away from the stenotic ipsilateral carotid artery, and reverse flow was defined as blood flow into the carotid artery. The ICA/CCA ratio was also calculated and defined as PSV of ICA divided by PSV of CCA. The degree of carotid stenosis was calculated according to the method used in the European Carotid Surgery Trial. ${ }^{12,13}$ All patients showed $>70 \%$ degree of stenosis over the symptomatic carotid system.

\section{Statistical analysis}

All statistical analyses were performed using the statistical package SPSS for Windows (version 16.0; SPSS Inc., Chicago, IL, USA). Pre- and poststenting mRS scores were compared to determine patient outcomes and classified as improved, stationary, or deteriorated. Statistical comparisons were conducted using Pearson's $\chi^{2}$ test.

To test the association between net $\mathrm{mRS}$ change and prestenting exam variables, net mRS was defined as (prestenting mRS value) - (poststenting mRS value). Positive (mRS[+]) values $(>0)$ indicated improvement and negative or stationary $(\mathrm{mRS}[-])$ values $(\leq 0)$ deterioration in patient condition. Comparison of groups according to net mRS change was conducted using all available recorded variables. Mann-Whitney $U$-test was used to determine differences in the mean values of continuous variables between the two groups. Categorical variables were compared using the $\chi^{2}$ test, or Fisher's exact test, where appropriate. Univariate or multivariate logistic regression was employed to assess the significance of risk factors and to obtain odds ratios (ORs). A $P$-value $<0.050$ was considered statistically significant.

Patients were divided into four groups with respect to age: $<65$ years $(n=38), 65-74$ years $(n=52), 75-84$ years $(\mathrm{n}=48)$, and $\geq 85$ years ( $\mathrm{n}=6$ persons). ${ }^{14-16}$

Further age group analysis was conducted, and comparison of each groups was performed using all available recorded variables before stenting treatment. Kruskal-Wallis test was used to determine whether any variable exhibited a significant difference among the three groups, and Jonckheere-Terpstra test was utilized to test for significance of trends. ${ }^{17,18}$

Neuroradiological examinations included MRI/A, CTA/P imaging, digital subtraction angiography, and stenting procedure. These have been described in detail in an earlier study by our group ${ }^{19}$ (Supplementary material and Figure 1).

\section{Results}

Baseline characteristics before CAS are presented in Table 1. The median age of study participants was 72 years. The pre- and
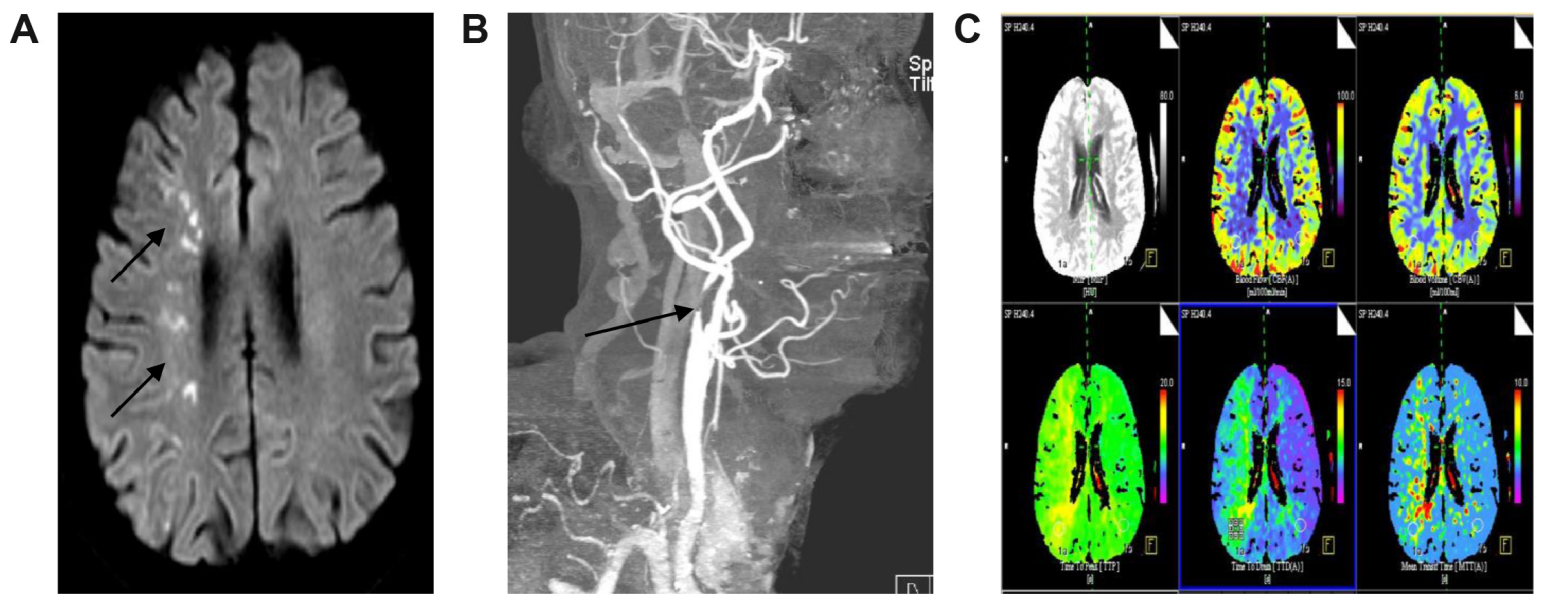

Figure I (Continued) 

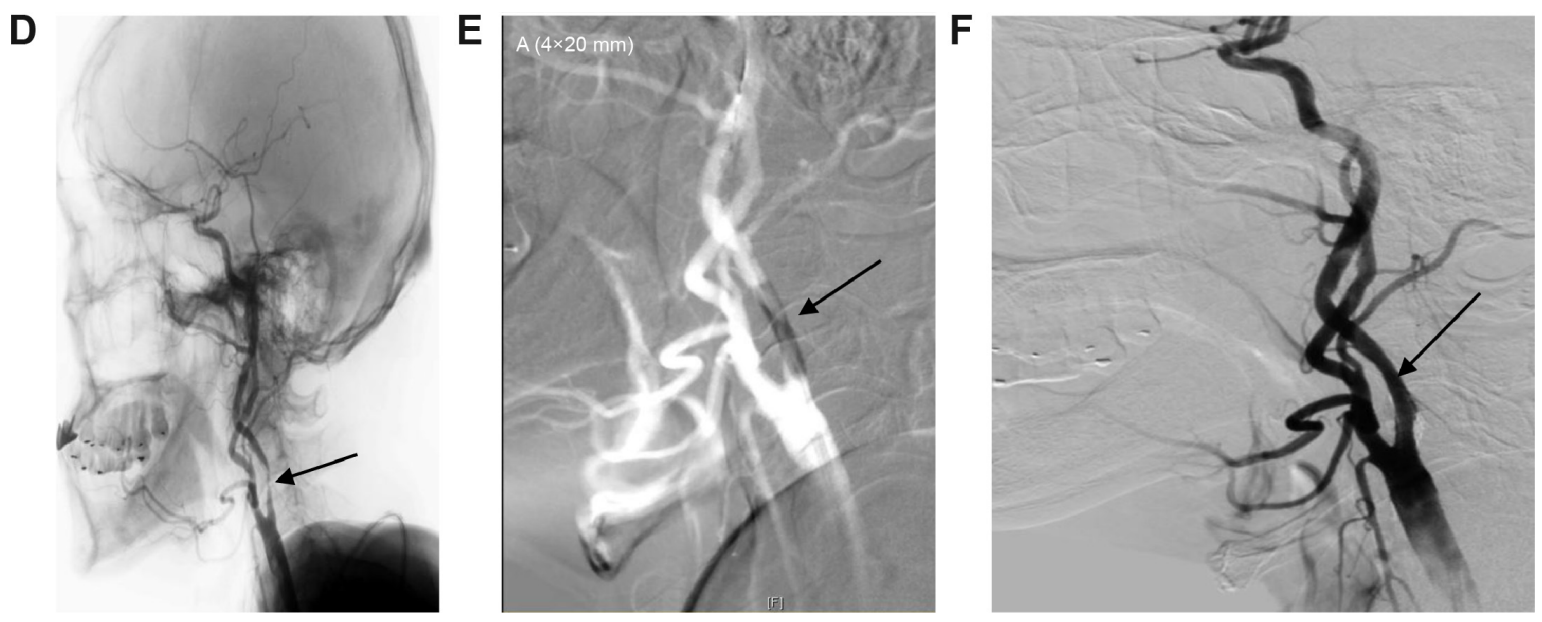

Figure I A stroke patient of right side severe internal carotid artery stenosis ( $>50 \%$ lumen reduction) treated with stenting revascularization.

Notes: (A) A 70-year-old male suffered from abrupt onset of left upper limb weakness and slurred speech 12 hours before admission to our stroke services. Diffusionweighted magnetic resonance imaging demonstrated multiple infarcts in right corona radiate along with anterior and internal border zone regions (black arrows). (B) A three-dimensional computed tomography angiography demonstrates a severe short-segmental stenosis (black arrow) at right internal carotid artery. Parameters included field of view, I5 $15 \mathrm{~cm}$; section thickness, I mm; imaging time, 60 seconds. (C) TTP, MTT, and TTD maps of computed tomography perfusion scan showed a large perfusion delay that affects the territory of the right middle cerebral artery. (D) Pretreatment angiogram of right internal carotid artery showed $78 \%$ stenosis of the proximal cervical internal carotid (black arrow). (E) After advanced a 7 Fr guide catheter, a 0.014" guidewire was advanced through the stenosis and an AngioGuard XP system (Cordis, Miami Lakes, FL, USA) was opened distally to the stenosis. Angioplasty with a $4 \times 20 \mathrm{~mm}$ Sterling ES balloon dilatation catheter (black arrow). (F) Posttreatment angiogram of right internal carotid artery (black arrow).

Abbreviations: MTT, mean transit time; TTD, time to drain; TTP, time to peak.

Table I Baseline patient clinical characteristics

\begin{tabular}{ll}
\hline $\mathbf{N}=$ I 44 & $\begin{array}{l}\text { No (\%) or } \\
\text { median (range) }\end{array}$ \\
\hline Age (years) & $72(46-89)$ \\
Sex (male) & $120(83.3)$ \\
Body mass index $\left(\mathrm{kg} / \mathrm{m}^{2}\right)$ & $23.40(14.8-36.3)$ \\
Weight $(\mathrm{kg})$ & $60(39-90)$ \\
Height $(\mathrm{cm})$ & $160(143-175)$ \\
Systolic blood pressure $(\mathrm{mmHg})$ & $140(88-220)$ \\
Diastolic blood pressure $(\mathrm{mmHg})$ & $77.50(52-126)$ \\
Admission Barthel index & $85(0-100)$ \\
Admission NIHSS score & $5(0-30)$ \\
Degree of stenosis in symptomatic side of & $76.4(52.6-95)$ \\
carotid artery (\%) & \\
Creatinine (mg/dL) & $1.065(0.2-5.8)$ \\
Uric acid (mg/dL) & $6.00(2.1-12.3)$ \\
Glycated hemoglobin (\%) & $6.30(4.1-13.6)$ \\
Fasting blood sugar (g/dL) & $114.5(69-264)$ \\
Admission low-density lipoprotein (mg/dL) & $101.50(36-189)$ \\
Admission high-sensitivity C-reactive & $4.56(\mathrm{I}-17)$ \\
protein (mg/L) & \\
Risk factor survey & \\
Chronic kidney disease & $22(15.3)$ \\
Gouty arthritis & $24(16.7)$ \\
Chronic heart failure & $3(2.1)$ \\
Atrial fibrillation & $5(3.5)$ \\
Hypertension & $117(81.3)$ \\
Diabetes mellitus & $56(38.9)$ \\
Dyslipidemia & $102(70.8)$ \\
\hline
\end{tabular}

Abbreviation: NIHSS, National Institute of Health Stroke Scale. poststenting $\mathrm{mRS}$ score for each patient is summarized in Table 2. In total, 72/144 patients had improved mRS scores with improvement of either 1 or 2 points, 71/144 had stationary $\mathrm{mRS}$ scores, and one patient had poorer mRS score.

Critical variables associated with functional improvement from baseline $\mathrm{mRS}$ score after stenting are shown in Table 3. The ratio of cerebral blood volume (rCBV), BI, and hsCRP were all factors that were significantly associated with $\mathrm{mRS}$ score improvement.

Results of the univariate and multivariate regression analysis are shown in Table 4. Of the three critical prestenting parameters, multivariate analysis showed that lower admission BI $(\leq 60)$ differed significantly between the two

Table 2 Changes of $m R S$ before and after stenting treatment

\begin{tabular}{llllllll}
\hline $\begin{array}{l}\text { Poststenting } \\
\text { mRS (N) }\end{array}$ & \multicolumn{7}{l}{ Prestenting $\mathbf{m R S}(\mathbf{N})$} \\
\cline { 2 - 8 } & $\mathbf{0}$ & $\mathbf{I}$ & $\mathbf{2}$ & $\mathbf{3}$ & $\mathbf{4}$ & $\mathbf{5}$ & Total \\
\hline 0 & $\mathrm{I}$ & 40 & 0 & 0 & 0 & 0 & $4 \mathrm{I}$ \\
$\mathrm{I}$ & 0 & 19 & 18 & $\mathrm{I}$ & 0 & 0 & 38 \\
2 & 0 & 0 & 18 & 9 & 0 & 0 & 27 \\
3 & 0 & 0 & 0 & 10 & 4 & 0 & 14 \\
4 & 0 & 0 & 0 & 0 & 22 & 0 & 22 \\
5 & 0 & 0 & 0 & 0 & 0 & $\mathrm{I}$ & $\mathrm{I}$ \\
6 & 0 & 0 & 0 & 0 & 0 & 1 & 1 \\
Total & & & & & & & 144 \\
\hline
\end{tabular}

Notes: Improvement in $m R S, n=72$; stationary $m R S, n=71$; deterioration in $m R S, n=1$. Abbreviation: $m R S$, modified Rankin scale. 
Table 3 Critical variables associated with functional improvement from baseline $\mathrm{mRS}$ score after stenting

\begin{tabular}{llll}
\hline $\begin{array}{l}\text { Prestenting } \\
\text { predictors }\end{array}$ & $\begin{array}{l}\text { Net mRS } \\
\text { improvement } \\
(-) \mathbf{n}=\mathbf{7 2}\end{array}$ & $\begin{array}{l}\text { Net mRS } \\
\text { improvement } \\
(+) \mathbf{n}=\mathbf{7 2}\end{array}$ & P-value \\
\hline $\begin{array}{l}\text { Ratio of cerebral blood } \\
\text { volume, median (range) }\end{array}$ & $\mathrm{I} .4 \mathrm{I}(0.45-3.95)$ & $\mathrm{I} .20(0.46-2.93)$ & 0.043 \\
$\begin{array}{l}\text { Admission Barthel index, } \\
\text { median (range) }\end{array}$ & $75(0-100)$ & $85(10-100)$ & 0.019 \\
$\begin{array}{l}\text { Admission high-sensitivity } \\
\begin{array}{l}\text { C-reactive protein, } \\
\text { median (range) }\end{array}\end{array}$ & & & \\
\hline
\end{tabular}

Notes: Net mRS improvement $=$ (prestenting mRS value) - (poststenting mRS value); values $>0$ indicate improvement and values $\leq 0$ indicate stationary or deterioration in patient condition.

Abbreviation: mRS, modified Rankin scale.

mRS score groups (OR 4.13; 95\% CI 2.35-10.97; $P=0.041$ ). Lower values for both CRP and $\mathrm{rCBV}$ were significantly associated with improved $\mathrm{mRS}$ scores $(P=0.032$ and $P=0.01$, respectively).

Patients were stratified into one of three groups based on age. The age group analysis is presented in Table 5 . The three different age groups varied significantly in four factors: ICA/CCA ratio $(P=0.011), \mathrm{BI}$ at admission $(P=0.019)$, ipsilateral ICA RI $(P=0.003)$, and glycated hemoglobin $(P=0.039)$.

In addition, as age increased from 65 to 85 years, the median values of the ICA/CCA ratio and ipsilateral ICA RI had a tendency to increase, while admission BI and glycated hemoglobin decreased (Jonckheere-Terpstra test; $P<0.050$ ).

Patients in the $<65$ and $65-74$ years age groups were significantly more likely to have a preexisting diagnosis of diabetes mellitus when compared with patients $>74$ years ( $P=0.012$; Table 6$)$. Older patients $>74$ years were significantly more likely to have a diagnosis of chronic kidney disease compared with patients in the younger age groups $(P=0.006)$. There was no significant association between age group and net $\mathrm{mRS}$ improvement ( $P=0.371$; Table 7). Ipsilateral ICA RI was significantly associated with age, with $15 / 54(28 \%)$ patients $\geq 75$ years having high RI values $(\geq 0.75)$ compared with only $6 / 38(16 \%)$ of patients $<65$ years of age $(P=0.001$; Table 8$)$.

\section{Discussion}

Patients with a moderate to severe degree of carotid stenosis who experience a primary ischemic stroke are at significantly increased risk of recurrent stroke, and a 7.8\% recurrence rate has been reported in Taiwanese population-based data. ${ }^{3}$ The current guideline recommends CEA, particularly in elderly patients, ${ }^{20}$ and CAS is indicated for young and middleaged symptomatic patients with carotid lumen reduction measuring $>70 \%$ by noninvasive imaging or $>50 \%$ by catheter-based imaging. CAS has advantages in that it can ensure prompt management and prevent recurrent stroke, especially for first-ever elderly stroke patients, is less invasive than CEA, and requires shorter operation time. CAS has been shown to be as beneficial as CEA in patients with angiographic evidence of $>60 \%$ stenosis or ultrasonographic evidence of $70 \%$ stenosis. $^{21}$

Although CAS is a viable alternative to $\mathrm{CEA}^{22,23}$ in some patient groups, a recent systematic review and meta-analysis observed that for CAS compared with CEA, there is significant periprocedural risk of stroke or death in patients aged 70-74 years, with a hazards ratio of 2.09 (95\% CI 1.32 3.32). ${ }^{24}$ However, age was not associated with postprocedural stroke risk for either CAS or CEA.

In our center, only the CAS procedure is available, providing a unique opportunity to further investigate CAS outcomes in the elderly first-ever ischemic stroke population. In the present study, all patients underwent CAS even though most were of advanced age. Nonetheless, we found that stenting resulted in good long-term outcomes. The cohort we have investigated had a median age of 70 years, and yet favorable outcomes following CAS were observed with 72/144 (50\%) patients exhibiting improved functioning following the procedure (Table 2). In addition, there were no stroke recurrence events, myocardial infarction, or other vascular events in the periprocedural period or at 1-year follow-up.

A number of clinical carotid ultrasound parameters have been investigated for their association with patient outcomes following ischemic stroke. For example, previous studies have reported that carotid plaque type is strongly associated with functional outcome of patients after ischemic

Table 4 Predictors of midterm functional outcome

\begin{tabular}{|c|c|c|c|c|c|c|}
\hline \multirow[t]{2}{*}{ Predictor } & \multicolumn{3}{|c|}{ Univariate analysis } & \multicolumn{3}{|c|}{ Multivariate analysis } \\
\hline & OR & $95 \% \mathrm{Cl}$ & $P$-value & OR & $95 \% \mathrm{Cl}$ & $P$-value \\
\hline Ratio of cerebral blood volume & 0.573 & $0.324-0.917$ & 0.049 & 0.632 & $0.321-0.932$ & 0.01 \\
\hline Admission Barthel index $(\leq 60)$ & 2.379 & $1.215-4.437$ & $<0.01$ & 4.132 & $2.345-10.970$ & 0.041 \\
\hline Admission high-sensitivity C-reactive protein & 0.823 & $0.725-0.991$ & 0.02 & 0.832 & $0.732-0.887$ & 0.032 \\
\hline
\end{tabular}

Abbreviations: $\mathrm{Cl}$, confidence interval; OR, odds ratio. 
Table 5 Critical clinical parameters differentiating various age groups

\begin{tabular}{|c|c|c|c|c|}
\hline \multirow{2}{*}{$\begin{array}{l}\text { Median } \\
\text { (range) }\end{array}$} & \multicolumn{4}{|l|}{ Age group } \\
\hline & $\begin{array}{l}<65 \text { years } \\
(n=38)\end{array}$ & $\begin{array}{l}65-74 \text { years } \\
(n=52)\end{array}$ & $\begin{array}{l}\geq 75 \text { years } \\
(n=54)\end{array}$ & $P$-value \\
\hline ICA/CCA & 3.45 & 5.06 & 5.20 & 0.011 \\
\hline ratio & $(I-8)$ & $(I-13)$ & $(I-23)$ & \\
\hline Admission & 85 & 85 & 75 & 0.019 \\
\hline Barthel index & $(30-100)$ & $(40-100)$ & $(0-100)$ & \\
\hline Ipsilateral & 0.58 & 0.66 & 0.675 & 0.003 \\
\hline ICA RI & $(0.24-0.83)$ & $(0.40-1.00)$ & $(0.36-0.96)$ & \\
\hline Glycated & 6.70 & 6.70 & 6.01 & 0.039 \\
\hline hemoglobin & $(4-13)$ & $(5-13)$ & $(4-10)$ & \\
\hline
\end{tabular}

Abbreviations: CCA, common carotid artery; ICA, internal carotid artery; $\mathrm{RI}$, resistance index.

stroke. ${ }^{25-27}$ In our study, however, we did not observe such an association.

IMT has been shown to be predictive of cardiovascular disease and stroke. ${ }^{28-32}$ To the best of our knowledge, however, no studies have investigated the relationship between IMT and functional outcome after stenting in patients with first-ever ischemic stroke. Our results show that there is no association between IMT and poststenting outcome. Reversal of blood flow in the OA is another commonly observed phenomenon, particularly in Asian patients with stroke and concomitant high-grade carotid stenosis. The reversal of OA flow indicates intracranial blood insufficiency that necessitates the use of extracranial arteries to maintain blood flow. Reversal of blood flow in the OA is often considered a sign of exhausted basal arteries, thus suggesting potential recurrent stroke. ${ }^{33,34}$ However, we observed no significant difference in OA reversal between patients with stationary mRS score after stenting and patients with improved $\mathrm{mRS}$ score after stenting.

RI, a clinical index generated from carotid ultrasound, ${ }^{35}$ reflects the degree of resistance of blood flow to the downstream vascular bed. An RI $\geq 0.75$ denotes increased resistance, which can be due to various factors, including obstruction. As CCA and ICA supply the majority of blood

Table 6 Critical clinical parameters differentiating various age groups

\begin{tabular}{lllll}
\hline $\begin{array}{l}\text { Prestenting } \\
\text { predictors }\end{array}$ & \multicolumn{3}{l}{ Age group } & \\
\cline { 2 - 5 } & $\begin{array}{l}<\mathbf{6 5} \text { years } \\
(\mathbf{n}=\mathbf{3 8})\end{array}$ & $\begin{array}{l}\mathbf{6 5 - 7 4} \text { years } \\
(\mathbf{n}=\mathbf{5 2})\end{array}$ & $\begin{array}{l}\geq \mathbf{7 5} \text { years } \\
\mathbf{(}=\mathbf{5 4})\end{array}$ & P-value \\
\hline $\begin{array}{l}\text { Diabetes mellitus (+), } \\
\mathrm{n}(\%)\end{array}$ & $\mathbf{6}(42.1)$ & $27(51.9)$ & $13(24.1)$ & 0.012 \\
$\begin{array}{l}\text { Chronic kidney } \\
\text { disease }(+), \mathrm{n}(\%)\end{array}$ & $0(0)$ & $9(17.3)$ & $13(24.1)$ & 0.006 \\
\hline
\end{tabular}

Table 7 Correlation between age groups and mRS improvement

\begin{tabular}{|c|c|c|c|c|}
\hline \multirow[t]{2}{*}{ Net mRS } & \multicolumn{4}{|l|}{ Age group } \\
\hline & $\begin{array}{l}<65 \text { years } \\
(n=38)\end{array}$ & $\begin{array}{l}\text { 65-74 years } \\
(n=52)\end{array}$ & $\begin{array}{l}\geq 75 \text { years } \\
(n=54)\end{array}$ & $P$-value \\
\hline $\begin{array}{l}\text { Net mRS improvement } \\
(-), \mathrm{n}(\%)\end{array}$ & I 8 (47.4) & $23(44.2)$ & 31 (57.4) & $0.37 I$ \\
\hline $\begin{array}{l}\text { Net mRS improvement } \\
(+), \mathrm{n}(\%)\end{array}$ & $20(52.6)$ & $29(55.8)$ & $23(42.6)$ & \\
\hline
\end{tabular}

Abbreviation: mRS, modified Rankin scale.

to the intracranial hemispheres, their RI values are typically lower than the that of ECA under normal circumstances ( $\mathrm{CCA}$ and $\mathrm{ICA}<0.75, \mathrm{ECA}>0.75)$. This index is a widely used parameter to check downstream stenosis and vasomotor reserve capacity. ${ }^{35}$ Interestingly, and in contrast to other studies, we have observed that the majority of patients have values of RI $<0.75$ (109/144). We also observed a significant relationship between increasing age and $\mathrm{RI} \geq 0.75$ (Tables 5 and 8 ). This could be partially explained by the hypothesis that as age increases, vessel wall flexibility declines preventing adjustment to atherosclerotic changes.

Patients with carotid stenosis and concomitant ipsilateral middle cerebral artery stenosis often have an inferior outcome after carotid stenting because of the poor ipsilateral collateral distribution. ${ }^{36-38}$ In this study, MRI/MRA findings did not reveal an association between long-term functional outcome and ipsilateral middle cerebral artery stenosis. Insignificant findings were observed in patients with concomitant intracranial posterior circulation stenosis and stroke location found on the cerebral parenchyma. Studies have also investigated various CT perfusion parameters to assess the immediate pre- and poststenting cerebral perfusion state. ${ }^{39-47}$ However, none of the parameters seemed to be associated with the long-term functional outcome.

In our study, the ratio of $\mathrm{rCBV}$, admission $\mathrm{BI}$, and hsCRP were significantly associated with $\mathrm{mRS}$ score changes at

Table 8 Correlation between age groups and ipsilateral ICA RI value

\begin{tabular}{|c|c|c|c|c|}
\hline \multirow{2}{*}{$\begin{array}{l}\text { Ipsilateral } \\
\text { ICA RI }\end{array}$} & \multicolumn{4}{|l|}{ Age group } \\
\hline & $\begin{array}{l}<65 \text { years } \\
(n=38)\end{array}$ & $\begin{array}{l}65-74 \text { years } \\
(n=52)\end{array}$ & $\begin{array}{l}\geq 75 \text { years } \\
(n=54)\end{array}$ & $P$-value \\
\hline $\begin{array}{l}\mathrm{RI} \geq 0.75 \\
\mathrm{n}(\%)\end{array}$ & $6(15.7)$ & I4 (26.9) & I5 (27.7) & 0.001 \\
\hline $\begin{array}{l}\text { RI <0.75, } \\
\text { n (\%) }\end{array}$ & $32(84.3)$ & $38(73.1)$ & $39(72.3)$ & \\
\hline
\end{tabular}

Abbreviation: ICA RI, internal carotid artery resistance index. 
12-month follow-up. These parameters may have potential as predictors of outcome and suitability for CAS. Lower values of the $\mathrm{rCBV}$, a parameter derived from the CTA/P, may predict better outcomes. This is a factor seldom researched in the literature. Merckel et $\mathrm{al}^{48}$ found CAS improved cerebral blood flow dynamics in the affected cerebral hemisphere in both symptomatic and asymtomatic patients. They also observed that $\mathrm{rCBV}$ values at poststenting follow-up were much lower in symptomatic patients compared with asymptomatic patients. ${ }^{48}$ Lum et $\mathrm{al}^{49}$ found that $\mathrm{CT}$ angiography source imaging and CBV were better predictors of 24-hour infarct and outcome than noncontrast computed tomography.

$\mathrm{CBV}$, in conjunction with the cerebral blood flow index, can assist in predicting the outcome of an ischemic lesion. If both cerebral blood flow index and CBV are decreased, there is a risk of tissue damage, and when both are substantially decreased, it is probable that irreversible damage has already occurred. ${ }^{50}$ Lower levels of hsCRP were also predictive of better outcomes following CAS. hsCRP, an indicator of systemic inflammation, is a well-characterized parameter used to assess the risk of cardiovascular disease including stroke and myocardial infarction. ${ }^{51}$

Strengths of this study include that there was sufficient follow-up time, of at least 12 months, between administering the first and subsequent mRS test allowing time for patients' neurological condition to stabilize following CAS. Furthermore, follow-up mRS was performed at one outpatient clinic which facilitated consistency and comparability of results.

Our study has several limitations. First, this was a study that used data on a relatively small $(n=144)$ number of patients treated at a single medical center. The small study size reduces the statistical power of our analysis, and therefore, results must be interpreted with caution. Second, all patients were of Asian origin, and therefore, the results might be applicable only to the Asian population. Third, many of the patients took medications to control underlying comorbidities such as gouty arthritis and hyperlipidemia in the poststenting phase. Such medications might potentially alter the follow-up mRS values, resulting in interpretation errors. Fourth, carotid duplex and neuroradiological examinations did not have both pre- and poststenting data for comparison. Thus, the immediate effect of carotid stenting could not be clearly presented.

\section{Conclusion}

Our findings indicate that in our elderly patient series, CAS may benefit a significant proportion of carotid stenotic patients regardless of age. The prestenting parameters of $\mathrm{rCBV}$, admission BI, and hsCRP may be useful predictors of poststenting outcomes.
The ICA/CCA ratio, admission BI, ipsilateral ICA RI, glycated hemoglobin, and history of diabetes mellitus and chronic kidney disease differed significantly with age and may be useful parameters for differentiating suitability for CAS.

\section{Acknowledgments}

We specially thank Ping-Yi Lin, $\mathrm{PhD}$, of Changhua Christian Hospital for her constructive comments. This project is partially supported by Ministry of Science and Technology and Big Data Research Center of National Chiao Tung University, Taiwan.

\section{Author contributions}

Chih Ming Lin, MD, MPH: collecting data and study design. Yu-Jun Chang, PhD: biostatistical analysis. Chi-Kuang Liu, MD: data collection. Cheng-Sheng Yu, MS: data analysis. Henry Horng-Shing Lu, PhD: study design and data analysis. All authors contributed toward data analysis, drafting and critically revising the paper and agree to be accountable for all aspects of the work.

\section{Disclosure}

The authors report no conflicts of interest in this work.

\section{References}

1. Adams HP Jr, Bendixen BH, Kappelle LJ, et al. Classification of subtype of acute ischemic stroke. Definitions for use in a multicenter clinical trial. TOAST. Trial of Org 10172 in Acute Stroke Treatment. Stroke. 1993;24(1):35-41.

2. Madden KP, Karanjia PN, Adams HP Jr, Clarke WR. Accuracy of initial stroke subtype diagnosis in the TOAST study. Trial of ORG 10172 in Acute Stroke Treatment. Neurology. 1995;45(11):1975-1979.

3. Lee M, Wu YL, Ovbiagele B. Trends in incident and recurrent rates of first-ever ischemic stroke in Taiwan between 2000 and 2011. J Stroke. 2016;18(1):60-65.

4. Kolominsky-Rabas PL, Weber M, Gefeller O, Neundoerfer B, Heuschmann PU. Epidemiology of ischemic stroke subtypes according to TOAST criteria: incidence, recurrence, and long-term survival in ischemic stroke subtypes: a population-based study. Stroke. 2001;32(12): 2735-2740.

5. Papanagiotou $\mathrm{P}$, Roth $\mathrm{C}$, Walter $\mathrm{S}$, et al. Carotid artery stenting in acute stroke. J Am Col Cardiol. 2011;58(23):2363-2369.

6. Xia ZY, Yang H, Xu JX, et al. Effect of stenting on patients with chronic internal carotid artery occlusion. Int Angiol. 2012;31(4):356-360.

7. Kernan WN, Ovbiagele B, Black HR, et al. Guidelines for the prevention of stroke in patients with stroke and transient ischemic attack: a guideline for healthcare professionals from the American Heart Association/ American Stroke Association. Stroke. 2014;45(7):2160-2236.

8. Bonati LH, Dobson J, Featherstone RL, et al. Long-term outcomes after stenting versus endarterectomy for treatment of symptomatic carotid stenosis: the International Carotid Stenting Study (ICSS) randomised trial. Lancet. 2015;385(9967):529-538.

9. Shah S, Vanclay F, Cooper B. Predicting discharge status at commencement of stroke rehabilitation. Stroke. 1989;20(6):766-769.

10. Shah S, Vanclay F, Cooper B. Improving the sensitivity of the Barthel index for stroke rehabilitation. J Clin Epidemiol. 1989;42(8): 703-709. 
11. Gray-Weale AC, Graham JC, Burnett JR, Byrne K, Lusby RJ. Carotid artery atheroma: comparison of preoperative B-mode ultrasound appearance with carotid endarterectomy specimen pathology. J Cardiovasc Surg. 1988;29(6):676-681.

12. MRC European Carotid Surgery Trial: interim results for symptomatic patients with severe (70-99\%) or with mild (0-29\%) carotid stenosis. European Carotid Surgery Trialists' Collaborative Group. Lancet. 1991;337(8752):1235-1243.

13. Randomised trial of endarterectomy for recently symptomatic carotid stenosis: final results of the MRC European Carotid Surgery Trial (ECST). Lancet. 1998;351(9113):1379-1387.

14. Boscoe FP. Subdividing the age group of 85 years and older to improve US disease reporting. Am J Public Health. 2008;98(7):1167-1170.

15. Jacobs JM, Maaravi Y, Cohen A, Bursztyn M, Ein-Mor E, Stessman J. Changing profile of health and function from age 70 to 85 years. Gerontology. 2012;58(4):313-321.

16. Zizza CA, Ellison KJ, Wernette CM. Total water intakes of communityliving middle-old and oldest-old adults. J Gerontol A Biol Sci Med Sci. 2009;64(4):481-486.

17. Jonckheere AR. A distribution-free k-sample test against ordered alternatives. Biometrika. 1954;41:133-145.

18. Terpstra TJ. The asymptotic normality and consistency of Kendall's test against trend, when ties are present in one ranking. Indagationes Mathematicae. 1952;14:327-333.

19. Yu CS, Lin CM, Liu CK, Lu HH. Impact of baseline characteristics on outcomes of carotid artery stenting in acute ischemic stroke patients. Ther Clin Risk Manag. 2016;12:495-504.

20. Brott TG, Halperin JL, Abbara S, et al. 2011 ASA/ACCF/AHA/AANN/ AANS/ACR/ASNR/CNS/SAIP/SCAI/SIR/SNIS/SVM/SVS guideline on the management of patients with extracranial carotid and vertebral artery disease: executive summary: a report of the American College of Cardiology Foundation/American Heart Association Task Force on Practice Guidelines, and the American Stroke Association, American Association of Neuroscience Nurses, American Association of Neurological Surgeons, American College of Radiology, American Society of Neuroradiology, Congress of Neurological Surgeons, Society of Atherosclerosis Imaging and Prevention, Society for Cardiovascular Angiography and Interventions, Society of Interventional Radiology, Society of NeuroInterventional Surgery, Society for Vascular Medicine, and Society for Vascular Surgery. Developed in collaboration with the American Academy of Neurology and Society of Cardiovascular Computed Tomography. Catheter Cardiovasc Interv. 2013; 81(1):E76-E123.

21. Meschia JF, Bushnell C, Boden-Albala B, et al. Guidelines for the primary prevention of stroke: a statement for healthcare professionals from the American Heart Association/American Stroke Association. Stroke. 2014;45(12):3754-3832.

22. Kwak HS, Hwang SB, Jin GY, Hippe DS, Chung GH. Predictors of functional outcome after emergency carotid artery stenting and intra-arterial thrombolysis for treatment of acute stroke associated with obstruction of the proximal internal carotid artery and tandem downstream occlusion. AJNR Am J Neuroradiol. 2013;34(4):841-846.

23. Meyer SA, Gandhi CD, Johnson DM, Winn HR, Patel AB. Outcomes of carotid artery stenting in high-risk patients with carotid artery stenosis: a single neurovascular center retrospective review of 101 consecutive patients. Neurosurgery. 2010;66(3):448-453; discussion 453-444.

24. Howard G, Roubin GS, Jansen O, et al. Association between age and risk of stroke or death from carotid endarterectomy and carotid stenting: a meta-analysis of pooled patient data from four randomised trials. Lancet. 2016;387(10025):1305-1311.

25. Reilly LM, Lusby RJ, Hughes L, Ferrell LD, Stoney RJ, Ehrenfeld WK. Carotid plaque histology using real-time ultrasonography. Clinical and therapeutic implications. Am J Surg. 1983;146(2):188-193.

26. Steffen CM, Gray-Weale AC, Byrne KE, Lusby RJ. Carotid artery atheroma: ultrasound appearance in symptomatic and asymptomatic vessels. Aust N Z J Surg. 1989;59(7):529-534.

27. Van Damme H, Trotteur G, Vivario M, Limet R. Echographic characterization of carotid plaques. Acta Chir Belg. 1993;93(5):233-238.
28. Davis PH, Dawson JD, Riley WA, Lauer RM. Carotid intimal-medial thickness is related to cardiovascular risk factors measured from childhood through middle age: The Muscatine Study. Circulation. 2001;104(23):2815-2819.

29. Grant EG, Benson CB, Moneta GL, et al. Carotid artery stenosis: grayscale and Doppler ultrasound diagnosis - Society of Radiologists in Ultrasound consensus conference. Ultrasound Q. 2003;19(4): 190-198.

30. Pignoli P, Tremoli E, Poli A, Oreste P, Paoletti R. Intimal plus medial thickness of the arterial wall: a direct measurement with ultrasound imaging. Circulation. 1986;74(6):1399-1406.

31. Roman MJ, Naqvi TZ, Gardin JM, Gerhard-Herman M, Jaff M, MohlerE. American society of echocardiography report. Clinical application of noninvasive vascular ultrasound in cardiovascular risk stratification: a report from the American Society of Echocardiography and the Society for Vascular Medicine and Biology. Vasc Med. 2006;11(3):201-211.

32. Stein JH, Korcarz CE, Hurst RT, et al. Use of carotid ultrasound to identify subclinical vascular disease and evaluate cardiovascular disease risk: a consensus statement from the American Society of Echocardiography Carotid Intima-Media Thickness Task Force. Endorsed by the Society for Vascular Medicine. J Am Soc Echocardiogr. 2008;21(2):93-111; quiz 189-190.

33. Sung YF, Tsai CL, Lee JT, et al. Reversal of ophthalmic artery flow and stroke outcomes in Asian patients with acute ischemic stroke and unilateral severe cervical carotid stenosis. PloS One. 2013;8(12):e80675.

34. Tsai CL, Lee JT, Cheng CA, et al. Reversal of ophthalmic artery flow as a predictor of intracranial hemodynamic compromise: implication for prognosis of severe carotid stenosis. Eur J Neurol. 2013;20(3):564-570.

35. Pourcelot L. Applications cliniques de l'Examen Doppler Transcutane. Les Colloques de L'Institute National de la Sante et de la Recherche Medicale. INSERM. 1974;34:213-240.

36. Christou I, Felberg RA, Demchuk AM, et al. A broad diagnostic battery for bedside transcranial Doppler to detect flow changes with internal carotid artery stenosis or occlusion. J Neuroimaging. 2001;11(3):236-242.

37. Demchuk AM, Christou I, Wein TH, et al. Specific transcranial Doppler flow findings related to the presence and site of arterial occlusion. Stroke. 2000;31(1):140-146.

38. Jongen LM, van der Worp HB, Waaijer A, van der Graaf Y, Mali WP. Interrelation between the degree of carotid stenosis, collateral circulation and cerebral perfusion. Cerebrovasc Dis. 2010;30(3):277-284.

39. Duan Y, Li G, Yang Y, et al. Changes in cerebral hemodynamics after carotid stenting of symptomatic carotid artery. Eur J Radiol. 2012; 81(4):744-748

40. Jongen LM, Hendrikse J, Moll FL, Mali WP, van der Worp HB. Cerebral perfusion affects the risk of ischemia during carotid artery stenting. Cerebrovasc Dis. 2010;29(6):538-545.

41. Kluytmans M, van der Grond J, van Everdingen KJ, Klijn CJ, Kappelle LJ, Viergever MA. Cerebral hemodynamics in relation to patterns of collateral flow. Stroke. 1999;30(7):1432-1439.

42. Miteff F, Levi CR, Bateman GA, Spratt N, McElduff P, Parsons MW. The independent predictive utility of computed tomography angiographic collateral status in acute ischaemic stroke. Brain. 2009; 132(Pt 8):2231-2238.

43. Pinero P, Gonzalez A, Moniche F, et al. Progressive changes in cerebral perfusion after carotid stenting: a dynamic susceptibility contrast perfusion weighted imaging study. J Neurointerv Surg. 2014;6(7): $527-532$.

44. Suzuki Y, Nakajima M, Ikeda H, Abe T. Evaluation of hyperacute stroke using perfusion computed tomography. Neurol Med Chir. 2005;45(7):333-343; discussion 341-333.

45. Szarmach A, Halena G, Buczny J, et al. Evaluation of changes in the parameters of brain tissue perfusion in multi-slice computed tomography in patients after carotid artery stenting. Pol J Radiol. 2011; 76(3):7-15.

46. Thierfelder KM, Sommer WH, Baumann AB, et al. Whole-brain CT perfusion: reliability and reproducibility of volumetric perfusion deficit assessment in patients with acute ischemic stroke. Neuroradiology. 2013;55(7):827-835. 
47. Trojanowska A, Drop A, Jargiello T, Wojczal J, Szczerbo-Trojanowska M. Changes in cerebral hemodynamics after carotid stenting: evaluation with CT perfusion studies. J Neuroradiol. 2006;33(3):169-174.

48. Merckel LG, Van der Heijden J, Jongen LM, van Es HW, Prokop M, Waaijer A. Effect of stenting on cerebral CT perfusion in symptomatic and asymptomatic patients with carotid artery stenosis. AJNR Am J Neuroradiol. 2012;33(2):280-285.

49. Lum C, Ahmed ME, Patro S, et al. Computed tomographic angiography and cerebral blood volume can predict final infarct volume and outcome after recanalization. Stroke. 2014;45(9):2683-2688.
50. Tomandl BF, Klotz E, Handschu R, et al. Comprehensive imaging of ischemic stroke with multisection CT. Radiographics. 2003;23(3): 565-592.

51. Ridker PM. High-sensitivity C-reactive protein: potential adjunct for global risk assessment in the primary prevention of cardiovascular disease. Circulation. 2001;103(13):1813-1818. 


\section{Supplementary material Protocols of neuroradiological examinations}

\section{Magnetic resonance imaging and angiography}

Structural and functional magnetic resonance imaging and angiographic (MRI/A) examinations were performed using a 3-T (Magnetom Verio, Siemens Healthcare, Malvern, PA, USA) or a 1.5-T imager (Magnetom Aera; Siemens Healthcare) with a cervical coil. Standard protocol to evaluate a stroke including axial diffusion weighted imaging, apparent diffusion coefficient, and fluid-attenuated inversion-recovery sequences was followed. Three-dimensional time-of-flight MR angiography without contrast enhancement was performed in the transverse plane using a sliding interleaved $\mathrm{kY}$ acquisition sequence comprising six overlapping slabs of eleven sections and the following parameters: section thickness, $1.2 \mathrm{~mm}$; repetition time (milliseconds)/echo time (milliseconds), 242/7; flip angle, $20^{\circ}$; field of view, $200 \times 200 \mathrm{~mm}$; matrix, $205 \times 320 \mathrm{~mm}^{2}$. The final pixel size was $0.975 \times 0.625$ $\mathrm{mm}$. The entire imaging time was $\sim 7$ minutes. Contrastenhanced MR angiography was not routinely performed.

The following three parameters were derived from the MRI/A studies: 1) Ipsilateral middle cerebral artery stenosis or occlusion was diagnosed in patients with concomitant middle cerebral artery focal stenosis or occlusion on MRA and was confirmed by digital subtraction angiography (DSA) (1: disease, 0 : no disease). 2) Intracranial posterior circulation stenosis or occlusion was diagnosed in patients with incidental (either intracranial vertebral or basilar artery) focal stenosis or occlusion on MRA and was confirmed by DSA (1: disease, 0: no disease). 3) Stroke location was categorized as cortical, subcortical, or cortical and subcortical regions. We examined whether the locations revealed on MRI were associated with mRS scores (1: cortical, 2: subcortical, and 3: cortical and subcortical regions).

\section{Computed tomography angiography/perfusion imaging}

Computed tomography (CT) angiography examinations were performed using a second-generation dual-source CT scanner (SOMATOM Definition Flash; Siemens Healthcare). After an 18-gauge intravenous catheter was placed in the antecubital vein, $100 \mathrm{~mL}$ of contrast material (Iodixanol, Visipaque 320; GE Healthcare, Carrigtwohill, Ireland; or Iohexol, Omnipaque 350; GE Healthcare) was infused at a rate of $5 \mathrm{~mL} / \mathrm{s}$. An initial injection delay was estimated using the bolus-tracking technique, in which the threshold was 100 Hounsfield units. Scanning was performed using a dual-energy mode with a pitch of 0.9 , a rotation time of 0.28 seconds, and collimation of $2 \times 32 \times 0.6 \mathrm{~mm}$ at $100 \mathrm{kV} / 150 \mathrm{ref} \mathrm{mAs}$ (Tube A) and Sn140 kV/178 ref mAs (Tube B). The scanned area extended from the aortic arch to the top of the neurocranium. CT images were reconstructed using a slice thickness of 0.6 $\mathrm{mm}$, increment of $0.3 \mathrm{~mm}$, and medium-smooth kernel. CT perfusion scans were subsequently performed with a contrast bolus of $50 \mathrm{~mL}$ of Omnipaque 350 (GE Healthcare). Perfusion data sets were postprocessed on a Siemens Multimodality Workplace Workstation (Siemens Healthcare), yielding mean transit time (MTT), cerebral blood volume (CBV), cerebral blood flow (CBF), time to peak (TTP), and time to drain (TTD) maps. The arterial input and venous outflow curves were analyzed to ensure complete data sets. The other CT perfusion parameters included difference in MTT (dMTT: ipsilateral MTT - contralateral MTT), MTT ratio (rMTT: ipsilateral MTT/contralateral MTT), CBV ratio (rCBV: ipsilateral $\mathrm{CBV} /$ contralateral $\mathrm{CBV}$ ), $\mathrm{CBV}$ index (ipsilateral CBV - contralateral CBV/contralateral CBV), $\mathrm{CBF}$ ratio (rCBF: ipsilateral $\mathrm{CBF} /$ contralateral $\mathrm{CBF}$ ), $\mathrm{CBF}$ index (ipsilateral $\mathrm{CBF}$ - contralateral $\mathrm{CBF}$ )/contralateral $\mathrm{CBF}$ ), TTP index: (ipsilateral TTP - contralateral TTP)/contralateral TTP), and TTD ratio (rTTD: ipsilateral TTD/contralateral TTD).

\section{DSA and stenting procedure}

Biplanar intra-arterial DSA was performed using a biplanar flap panel rotational angiography unit (Axiom Artis Zee; Siemens Healthcare). An image intensifier matrix of $1,024 \times 1,024$ pixels and a final pixel size of $0.37 \mathrm{~mm}$ was used. Using the right femoral artery approach, a 7-F catheter (Mach 1, Boston Scientific, Marlborough, MA, USA) was inserted into the right or left common carotid arteries near the bifurcation. Posteroanterior and lateral projection views were acquired at the level of the carotid bifurcation. A third projection with an oblique angle was acquired if overlapping vessels were noted on the original two projections. For each projection, $11 \mathrm{~mL}$ of nonionic iodinated contrast material (Omnipaque 350; GE Healthcare) was intra-arterially injected at a flow rate of $7 \mathrm{~mL} / \mathrm{s}$ by an automatic injector (Mark V ProVis, Medrad, Whippany, NJ, USA). Subsequently, the stenting procedure was performed. A guidewire was inserted into the carotid artery on either side of the stenotic region and an E-Z filter wire was used to prevent major complications, such as recurrent stroke, caused by distal embolic migration. Overall, 5,000 units of prophylactic heparin were administered. A self-expandable Carotid Wallstent was used $(7 \times 30$ $\mathrm{mm})$. The stent was delivered coaxially through the guiding catheter into the stenotic area (Figure 1). 


\section{Publish your work in this journal}

Clinical Interventions in Aging is an international, peer-reviewed journal focusing on evidence-based reports on the value or lack thereof of treatments intended to prevent or delay the onset of maladaptive correlates of aging in human beings. This journal is indexed on PubMed Central, MedLine,
Dovepress

CAS, Scopus and the Elsevier Bibliographic databases. The manuscript management system is completely online and includes a very quick and fair peer-review system, which is all easy to use. Visit http://www.dovepress. $\mathrm{com} /$ testimonials.php to read real quotes from published authors. 